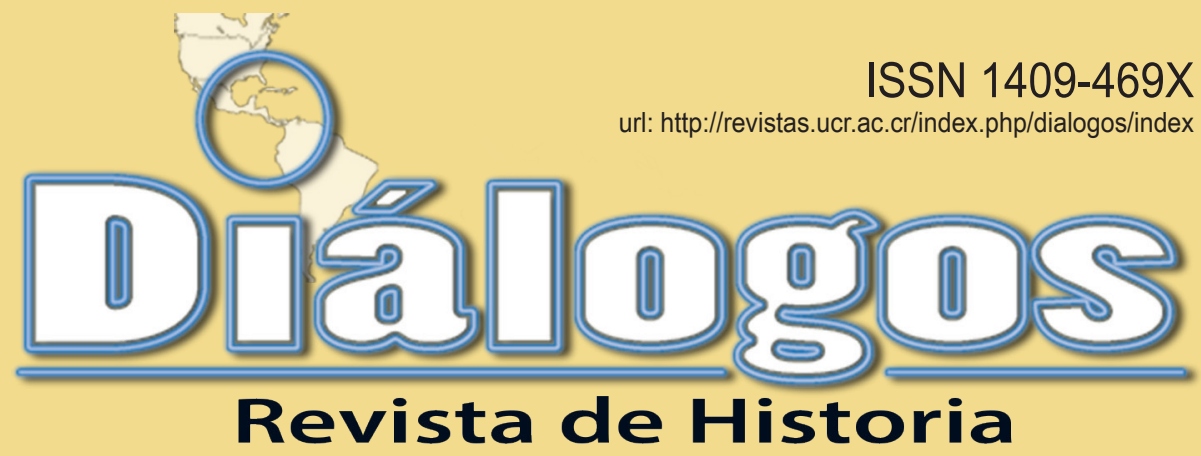

Escuela de Historia. Universidad de Costa Rica Volumen 15 Especial Región Occidente de Costa Rica - Octubre, 2014

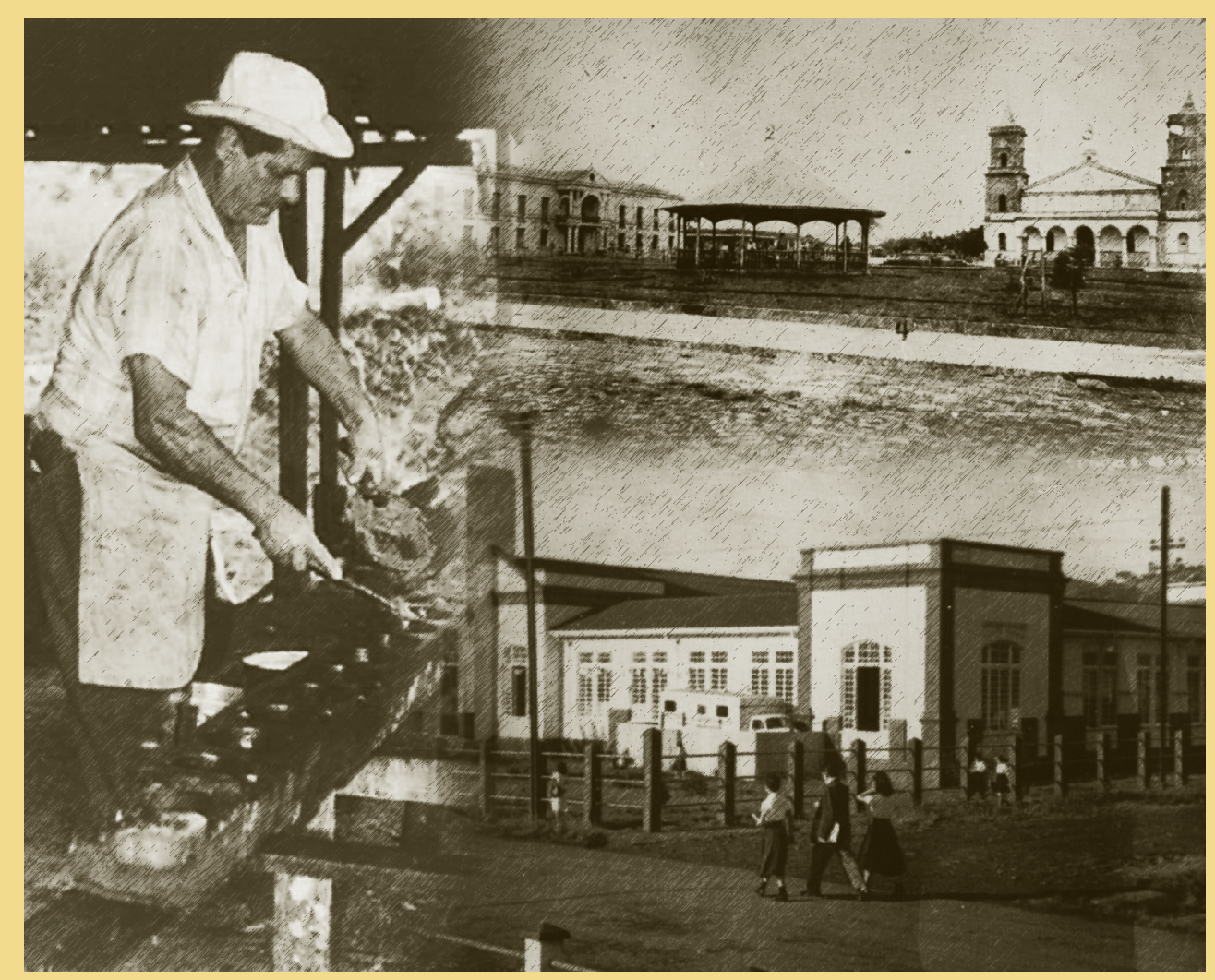

Director de la Revista: Dr. Juan José Marín Hernández juan.marinhernandez@ucr.ac.cr

Editor académico: Dr. David Díaz Arias - david.diaz@ucr.ac.cr

Editores invitados: M.Sc. William Solórzano Vargas - william.solorzano@ucr.ac.cr

M.Ed. Maynor Badilla Vargas - mainor.badilla@ucr.ac.cr

Editora técnica: M.Sc. Marcela Quirós G. - marcela.quiros@ucr.ac.cr 
Dr. Juan José Marín Hernández, Catedrático. Director del Centro de Investigaciones Históricas de América Central. Universidad de Costa Rica. Costa Rica. juan. marin@ucr.ac.cr

Dr. David Díaz Arias: Catedrático. Historia Política, Director del posgrado de Historia y Docente de la Escuela de Historia, Universidad de Costa Rica, Costa Rica.david.diaz@ucr.ac.cr

Dr. Ronny Viales Hurtado. Catedrático. Historia Económica y Social. Universidad de Costa Rica. Director de la Escuela de Historia. Costa Rica. ronny. viales@ucr.ac.cr

MSc. Francisco Enríquez. Historia Social. Universidad de Costa Rica. Costa Rica. francisco.enriquez@ucr. ac.cr

Dra. Ana María Botey. Historia de los movimientos sociales. Universidad de Costa Rica. Costa Rica. abotey@gmail.com

\section{Miembros del Consejo Asesor Internacional:}

Dr. José Cal Montoya. Universidad de San Carlos de Guatemala. Guatemala. jecalm@correo.url.edu.gt

Dr. Juan Manuel Palacio. Universidad Nacional de San Martín. Argentina.jpalacio@unsam.edu.ar

Dr. Eduardo Rey. Universidad de Santiago de Compostela. España. ereyt@usc.es

Dr. Heriberto Cairo Carou. Departamento de Ciencia Política y de la Administración III - Universidad Complutense de Madrid. España.hcairoca@cps.ucm.es

Dra. Rosa de la Fuente. Departamento de Ciencia Política y de la Administración III Universidad Complutense de Madrid. España. rdelafuente@cps. ucm.es

Dr. Javier Franzé. Departamento de Ciencia Política y de la Administración III Universidad Complutense de Madrid. España. javier.franze@cps.ucm.es

Dr. Jaime Preciado Coronado Departamento de Estudios Ibéricos y Latinoamericanos. Universidad de Guadalajara. México. japreco@hotmail.com

Dr. Gerónimo de Sierra. Vicerrector de la Universidade Federal da Integração Latino-Americana (UNILA) y Departamento de Sociología, Facultad de Ciencias
Sociales de la Universidad de la República. Uruguay. geronimo@fcs.edu.uy

Dr. Antonio Palazuelos. Departamento de Ciencia Política y de la Administración III - Universidad Complutense de Madrid. España. palazuelosa@cps. ucm.es

Dr. Werner Mackenbach. Universidad Potsdam. Alemania.werner.mackenbach@uni-potsdam.de

Dr. Guillermo Castro. Ciudad del Saber Panamá. Panamá.gcastro@cdspanama.org

Dra. Natalia Milanesio. University of Houston. Estados Unidos.nmilane2@Central.UH.EDU

Dr. Ricardo González Leandri. Consejo Superior de Investigaciones Científicas - España. España. rgleandri@gmail.com

Dra. Mayra Espina. Centro de Estudios Psicológicos y Sociológicos, La Habana. Cuba.mjdcips@ceniai.inf.cu

Dra. Montserrat Llonch. Departamento de Economía e Historia Económica Universidad Autónoma de Barcelona. España. montserrat.llonch@uab.es

Dra. Estela Grassi. Universidad de Buenos Aires. Argentina. estelagrassi@gmail.com

Dra. Yolanda Blasco. Universidad de Barcelona. España. yolandablasco@ub.edu

Dr. Alfredo Falero. Departamento de Sociología. Universidad de la República. Uruguay. alfredof@adinet. com.uy

\section{Portada:}

Fotografía: ( Collage "Campesinos en la producción de dulce en un trapiche de Rincón de Mora, Ran Ramón, 1987" ; "Panorámica del Antiguo Palacio Municipal, Antigua Iglesia, Parque y Kiosco de San Ramón, hacia 1920; y Escuela Jorge Washinton, San Ramón hacia 1955). Estas fotografías pertenecen a la Colección Fotográfica del Museo Regional de San Ramón- UCR. Montaje fotográfico: Lic. Juan Gabriel Madrigal Cubero ).

\section{Equipo Técnico Editorial:}

Diagramación y

Edición técnica:

M.Sc. Marcela Quirós Garita. marcela.quiros@ucr.ac.cr

Soporte técnico: Kevin Trejos Vargas

Revisión filológica: Baruc Chavarría Castro 
"Diálogos Revista Electrónica de Historia" se publica desde octubre de 1999.

\section{Diálogos está en los siguientes repositorios:}

\section{Dialnet}

http://dialnet.unirioja.es/servlet/

revista?tipo_busqueda=CODIGO\&clave_revista= 3325

\section{Latindex}

http://www.latindex.unam.mx/larga.php?opcion=1\&folio=12995;

\section{UCRindex}

http://www.revistas.ucr.ac.cr/

\section{Scielo}

http://www.scielo.cl/

\section{eRevistas}

http://www.erevistas.csic.es/

\section{REDALYC}

http://redalyc.uaemex.mx/src/inicio/FrmBusRevs2.jsp?iEdoRev=2\&cvepai=11;

\section{LANIC}

http://lanic.utexas.edu/la/ca/cr/indexesp.html;

Repositorio de Revistas Universidad de Costa Rica

http://www.latindex.ucr.ac.cr/

Directorio y recolector de recursos digitales del

Ministerio de Cultura de España

http://roai.mcu.es/es/inicio/inicio.cme

DOAJ Directory of open access \& Hybrid journals

http://www.doaj.org/doaj?func=byTitle\&hybrid=1\&query=D

Biblioteca de Georgetown

http://library.georgetown.edu/newjour/d/msg02735.html

Asociación para el Fomento de los Estudios Históricos

en Centroamérica

http://afehc.apinc.org/index.php?action=fi_aff\&id=1774

Universidad de Saskatchewan, Canadá

https://library.usask.ca/ejournals/view/1000000000397982

Monografias

http://www.monografias.com/Links/Historia/more12.shtm

\section{Hispanianova}

http://hispanianova.rediris.es/general/enlaces/hn0708.htm

Universidad del Norte, Colombia

http://www.uninorte.edu.co/publicaciones/memorias/enlaces.htm

Universidad Autónoma de Barcelona

http://seneca.uab.es/historia/hn0708.htm

Repositorio Invenia - Gestión del Conocimiento http://www.invenia.es/oai:dialnet.unirioja.es:ART0000086144

\section{Enlace Académico}

http://www.enlaceacademico.org/biblioteca/

revistas-en-formato-digital-centroamerica/

\section{Electronic Resources}

http://sunzi1.lib.hku.hk/ER/detail/hkul/3987318

Revistas académicas en texto completo

http://web.prw.net/ vtorres/

Diálogos se anuncia en las siguientes instituciones y sitios académicos:

Maestroteca

http://www.maestroteca.com/detail/553/dialogos-revista-electronica-de-historia.htm/

Biblioteca de Georgetown

http://library.georgetown.edu/newjour/d/msg02735.html

Asociación para el Fomento de los Estudios Históricos en Centroamérica

http://afehc.apinc.org/index.php?action=fi_aff\&id=1774

Universidad de Saskatchewan, Canadá

https://library.usask.ca/ejournals/view/1000000000397982

Monografias

http://www.monografias.com/Links/Historia/more12.shtm

Hispanianova

http://hispanianova.rediris.es/general/enlaces/hn0708.htm

Universidad del Norte, Colombia

http://www.uninorte.edu.co/publicaciones/memorias/enlaces.htm

Universidad Autónoma de Barcelona

http://seneca.uab.es/historia/hn0708.htm

Repositorio Invenia - Gestión del Conocimiento

http://www.invenia.es/oai:dialnet.unirioja.es:ART0000086144

Enlace Académico

http://www.enlaceacademico.org/biblioteca/

revistas-en-formato-digital-centroamerical

\section{Electronic Resources}

http://sunzi1.lib.hku.hk/ER/detail/hkul/3987318

Revistas académicas en texto completo http://web.prw.net/ vtorres/

Diálogos Revista de Historia está catalogada por Sherpa Romeo como una revista verde.

La revista electrónica Diálogos es financiada por Vicerrectoría de Investigación de la Universidad de Costa Rica

Citado en: Scielo Dialnet - eRevistas - UCRindex Latindex - REDALYC - DOAJDirectorio y recolector de recursos digitales del Ministerio de Cultura de España

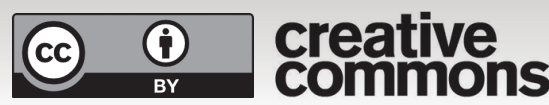




\title{
DENUNCIA Y DELITO EN EL MUNDO RURAL COSTARRICENSE: EL CASO DE NARANJO (1880-1924)
}

\author{
IMPEACHMENT AND CRIME IN THE COSTA RICAN RURAL AREA: \\ THE CASE OF NARANJO (1880-1924)
}

Eduardo González Ayala

\author{
Palabras clave \\ Delincuencia, legislación, capitalismo, tenencia de la tierra, Costa Rica.
}

\section{Keywords}

Crime, law, capitalism, land tenure, Costa Rica.

Fecha de recepción: 17 de mayo, 2014 - Fecha de aceptación: 1 de setiembre, 2014

\begin{abstract}
Resumen
El presente artículo tiene como objetivo primordial analizar tendencias relacionadas con el aumento de la denuncia y el delito en la población de Naranjo, un espacio rural, en el periodo comprendido entre 1880 y 1924. Este periodo está determinado por la aplicación del código penal de 1880 en Costa Rica, el cual tipificó una serie de delitos. La investigación se inscribe dentro de la historia social del crimen y para su elaboración se utilizó fuente primaria del Archivo Nacional de Costa Rica, así como la base de datos de dicha institución, mediante la cual fue posible cuantificar las denuncias que realizaron los habitantes de Naranjo durante el periodo señalado. El trabajo evidencia el aumento en las denuncias respecto a delitos que atentaron contra el patrimonio material en una época en la cual se consolidaba el capitalismo agrario, mientras que las denuncias respecto a crímenes contra la vida y el honor tendieron a disminuir o se mantuvieron estables durante el periodo.
\end{abstract}

\begin{abstract}
This article has as its primary objective to analyze trends related to the complaint and crime increased in Naranjo, a rural town in the period between 1880 and 1924. This period is determined by the application of the penal code of 1880 in Costa Rica, which defining a series of crimes. Research is part of the social history of crime and its development was primary source of the national archives of Costa Rica, as well as the database of such institution, through which it was possible to quantify the complaints that inhabitants of Naranjo made during the designated period. The article demonstrates the increase in complaints regarding offences that were against the material heritage in a time in which it is developing agrarian capitalism, while complaints regarding crimes against the life and honor tended to decrease or remained stable during the period.
\end{abstract}




\section{DENUNCIA Y DELITO EN EL MUNDO RURAL COSTARRICENSE: EL CASO DE NARANJO (1880-1924)}

\section{INTRODUCCIÓN}

El estudio de la historia social de la criminalidad se ha desarrollado de manera lenta en Costa Rica, con algunos trabajos destacados, pero relativamente escasos. La presente investigación pretende abordar, por un lado, el delito como un proceso social y, por otro lado, las denuncias al respecto interpuestas en Naranjo a finales del siglo XIX y principios del XX.

De esta forma, la visión del crimen, su denuncia y castigo se entrelazan con la formación del cantonato y la necesidad del Estado costarricense de ensanchar sus instituciones y sus mecanismos de control social. Paralelamente a estos procesos, se encuentran las formas de sanción, declaradas a nivel nacional a través del Código Penal de 1880, que son reinterpretadas por las comunidades, las cuales les otorgan a los delitos su propia significación.

Aunado a ello, interesa visualizar las dinámicas alrededor de las cuales se avizoraba la conflictividad en el periodo en estudio, así como sus repercusiones y las formas de dirimir las disputas. Con el fin de observar la incidencia de las denuncias y el papel institucional de las instancias judiciales, se han contabilizado y categorizado los delitos denunciados durante el periodo, lo cual permite un acercamiento a cierto tipo de conflictividad asociada cada vez más al capitalismo agrario, y menos a los valores tradicionales.

La sociedad naranjeña se debatía entre la conservación de las nociones tradicionales de honor y resolución de conflictos mediante el uso de una violencia legitimada socialmente, y las nociones nuevas del derecho moderno que se expandían gracias al ensanchamiento de la institucionalidad liberal, el control social racionalizado y la participación de profesionales en los juicios, lo cual implicaba nuevas formas de visualizar y atenuar el delito.

\section{ESTADO DE LA INVESTIGACIÓN}

La escasez de estudios sobre historia social de la criminalidad no demerita la importancia de aquellos que se han realizado en Costa Rica, sino que más bien devela las posibilidades de investigación en esta área, en la cual interesa profundizar en los mecanismos de control e institucionalización del delito y en aquellas instancias 
pertenecientes al Estado que se encargan de reprimirlo, como los tribunales, los cuerpos de policía y el sistema penitenciario (Emsley, 1996, p. 157), a los que se podrían añadir los sistemas de salud.

En Europa, los estudios sobre historia social de la criminalidad se han preocupado, entre otros aspectos, por analizar cómo la violencia comunitaria que encontraba su asidero en el imaginario social, era reemplazada por otros mecanismos de organización y de control de la criminalidad, además de las diferencias entre la punición del delito entre el mundo rural y urbano, y de la justicia oficial representada en el derecho moderno, respecto a los dispositivos "tradicionales" de resolución de conflictos (Cauvaud, 2003, pp. 168-174).

En el caso de Costa Rica, varios historiadores han abordado temas vinculados con la criminalidad y su manejo por parte del Estado, principalmente durante el siglo XIX e inicios del XX. Destacan aquí el trabajo de José Daniel Gil, quien analiza la incidencia de los delitos por homicidio en la provincia de Heredia, en el periodo 1885-1915, descubriendo que los asesinatos constituyen únicamente un arista pequeña de la conflictividad que se desarrolla al interior de las comunidades, y de los esfuerzos estatales por controlar y morigerar las costumbres de la población mediante el aparato institucional (Gil, 1997, pp. 52-57).

Por su parte, Juan José Marín aborda el tema de la prostitución en varias de sus investigaciones y demuestra en qué medida las prostitutas son objeto de control y estigmatización por parte de las autoridades, a la vez que responden al contexto de diversificación social y económica que experimenta San José en las últimas dos décadas del siglo XIX (Marín, 1994, pp. 53-54). Expone además cómo los intentos de morigeración y sanidad por parte de las autoridades usualmente chocaban con la reticencia de las trabajadoras sexuales, quienes desarrollaban mecanismos ingeniosos para escapar de las revisiones de salubridad y las redadas policiales (Marín, 2007, pp. 199-200), con el fin sobrevivir en el difícil mundo josefino, donde el capitalismo urbano se estaba asentando y empezaba a campear el individualismo y la "corrupción" de las costumbres tradicionales.

El tema del bandolerismo es abordado por Carlos Naranjo para el periodo comprendido entre 1850 y 1890. Naranjo presenta el caso de Pilar Jiménez, un bandolero josefino que en numerosas ocasiones estuvo en manos de la policía y fue trasladado a varios centros penitenciarios, entre ellos San Lucas. Asimismo, analiza el papel de las cárceles y las fugas de reclusos como ejemplos de la dinámica de disciplinamiento policial y de reacción de los reos ante esa disciplina. Finalmente, se ocupa del bandolerismo social y del robo como método de transgresión del statu quo en la sociedad decimonónica (Naranjo, 1994, pp. 86-101).

Sobre la Colonia e inicios de la Independencia, destacan los trabajos de Eugenia Rodríguez, que centran su atención en analizar el papel subordinado de 
las mujeres en una sociedad patriarcal, y cómo resultaban perjudicadas en los juicios, además de los niveles de conflictividad y violencia en el mundo colonial (Rodríguez, 2000, pp. 138-150). Aunado a ello, profundiza en las circunstancias particulares en las que eran cometidos ciertos delitos como estupro y violación, en los cuales se atentaba directamente contra las mujeres y cuyos castigos eran débiles o inexistentes, dependiendo de la posición social del imputado. Más allá de las denuncias, la autora concluye que la violencia sexual contra las mujeres era una práctica común (Rodríguez, 1994, p. 40).

Sobre la situación de grupos marginados, Ana Paulina Malavassi lleva a cabo un análisis de las condiciones en las cuales vivían los leprosos en el Lazareto, y la forma en la que eran vistos por la sociedad costarricense a finales de la Colonia e inicios de la Independencia. Expone cómo sobre los leprosos se desplegaban discursos y representaciones que iban desde la caridad y el asistencialismo, hasta la exclusión y el desprecio. El peso de estas representaciones se notaba en las políticas estatales y en el desarrollo de los mecanismos de control social, que pretendían alejar a los leprosos de las comunidades (Malavassi, 2003, p. 32).

Finalmente, Carlos Abarca hace un estudio sobre las sanciones penales y policiales hasta 1880, considerando la legislación, los códigos y los cambios históricos que se producen en las normativas. Además, asevera que la legitimación de la autoridad y el control de las poblaciones, sobre todo las de menos recursos, eran los objetivos primordiales de los gobernantes al establecer los códigos penales, en los cuales no se consideraba la situación socioeconómica o el contexto que provocaba la delincuencia (Abarca, 2001, pp. 266-276).

Los trabajos mencionados muestran cómo el ámbito del control social y la historia de la criminalidad, entendida en el sentido amplio de las relaciones sociales y productivas, la institucionalidad, los mecanismos represivos y de sanción, la cultura popular, la diversificación de la sociedad, la conflictividad cotidiana, los intereses particulares, la interiorización de valores y normas o el desacato de estas, así como el ejercicio del poder a nivel nacional y local, resultan una veta de investigación fructífera y de amplias posibilidades.

\section{FORMACIÓN SOCIOECONÓMICA E INSTITUCIONAL, CONFLICTIVIDAD Y CONTROL SOCIAL}

La sociedad costarricense de finales del siglo XIX se encontraba concentrada de manera notoria en el Valle Central, donde se podían obtener las mejores tierras, tanto desde el punto de vista de su ubicación geográfica, como de su fertilidad. El café le había dado a la floreciente sociedad las bases para su consolidación y para el 
desarrollo del capitalismo agrario, el cual implicó la búsqueda de nuevos espacios para cultivar, en la medida en que se iban agotando las fincas más cercanas a las principales ciudades.

Este desplazamiento, conocido como migración hacia la frontera agrícola, implicaba que los terrenos de la región occidental del Valle Central, donde se encuentra ubicado Naranjo, fueran apetecidos a tal punto que ya para finales del siglo XIX era posible denotar un avance en los niveles de colonización y aprovechamiento de tierras, proceso iniciado en el caso naranjeño en la década de 1830.

El Estado liberal se preocupó por establecer mecanismos de control del territorio, los cuales también estaban permeados por la idea de progreso material imperante en la época. Sin embargo, esta visión macro no impidió que ese mismo Estado, y quienes lo representaban como autoridades políticas, llevaran a la práctica una serie de medidas que se podrían catalogar de "intervencionistas" (Palmer, 1999, p. 100), en el sentido de que existe intervención estatal, pues se busca una participación activa en la economía y tener un impacto sobre ella.

Las políticas liberales que se aplicaron giraban principalmente sobre los ejes del poblamiento, la comunicación mediante caminos y el impulso de la agricultura como medio de desarrollo (Viales, 2000, pp. 100-102), por lo que dichas estrategias pretendían abarcar estos tres aspectos de una forma integral.

Algunos factores tenían un peso importante en la configuración socioeconómica y política de la Costa Rica decimonónica, entre ellos la escasez de mano de obra, que se convirtió en un factor de cuidado a la hora de sopesar las decisiones técnicas y políticas por parte de los gobiernos liberales. Las políticas migratorias encabezadas por la elite estaban orientadas al fomento de la migración procedente de Europa, con el fin de "mejorar la raza" y de extender los cultivos, de tal forma que se le diera mayor viabilidad económica al país. No obstante, esta migración "deseada" no siempre se dio de la forma en que hubiera preferido la clase dirigente, por lo que un proceso paralelo de gran importancia fue la migración interna, es decir, población que se desplazaba de acuerdo a las necesidades de obtener nuevas tierras para cultivar.

En el caso de los inmigrantes extranjeros que llegaron de manera masiva, estos no fueron tan significativos para la región occidental del Valle Central, contrario a la construcción del ferrocarril en el Atlántico, proceso en que fue constante y numeroso el flujo de inmigrantes procedentes primero de China e Italia, y posteriormente sobre todo de población afrocaribeña proveniente de Jamaica.

Un aspecto a considerar es el llamado "síndrome de incomunicación" (Viales, 2000, p. 106), que constituía un escollo importante a superar por los liberales, quienes observaban con preocupación cómo importantes regiones del país, que podían ser explotadas en términos económicos, no solo permanecían inhóspitas, 
sino que no existían las rutas para acceder a dichos lugares, ni las personas para colonizarlos.

El interés se centraba no solo en la vinculación con el mercado externo mediante el café (aunque este era uno de los objetivos liberales de mayor envergadura e importancia), sino además en la necesidad de contar con mejores caminos y puentes para el abastecimiento y mantenimiento del mercado interno, así como para las actividades comerciales hacia el Pacífico (Viales, 2000, p. 107).

Se considera que el territorio que comprende el cantón de Naranjo empezó a ser colonizado con la llegada en 1833 de don Judas Tadeo Corrales, quien delimitó una propiedad y se estableció con su familia en el poblado que en la actualidad se conoce como Candelaria. ${ }^{1}$

El poblamiento del señor Corrales y otros que llegaron en años posteriores, se encuentra contextualizado en las migraciones que se dieron en las primeras décadas del siglo XIX y que implicaron alejarse de las zonas cercanas a la capital y a la ciudad de Alajuela, hacia la frontera agrícola, para buscar tierras cultivables, proceso que recibió un empuje importante con el auge del café y con el aumento del precio de la tierra en las regiones más cercanas a San José.

Se trata del inicio de la colonización de la región de Occidente, proceso que se extendería rápidamente con la colonización y población de los territorios que ahora comprenden Grecia, San Ramón, Palmares y Valverde Vega. Además de nuevas tierras, esta región tenía ventaja para los migrantes por su lejanía de las autoridades y la suavización de los cobros de tributos o del diezmo, dados los limitados controles burocráticos (Molina, 1991, p. 48).

La primera migración de personas procedentes de las principales ciudades hacia Naranjo, se dio entre los años 1835 y 1865. Estos colonos buscaban tierras disponibles para cultivar y un lugar para asentarse con sus familias, por lo que los territorios de la zona de Occidente resultaron apetecibles.

La colonización regional fue un proceso que implicó no solamente la apropiación de terrenos, sino que requería la legitimación de estos mediante denuncios de tierras que se realizaban por medio del Estado, de tal forma que las propiedades recién colonizadas pudieran quedar "a derecho". Además, estaba presente el interés de crear nuevos caminos o "trochas" para animales, que permitieran comunicar a los pueblos y facilitar el transporte, la movilización y el comercio.

Las tierras denunciadas se dedicaron, primeramente, al cultivo de los granos básicos para la subsistencia, como maíz y frijoles, así como a la cría de animales (Torres, 2007, p. 30). Posteriormente se introdujeron otros cultivos como el trigo, el tabaco y el café, el cual se convertiría durante el siglo XX en el motor de la economía naranjeña y en una parte vital de su identidad local. 
Esta dinámica puede apreciarse en los censos agropecuarios, ya que por ejemplo, mientras en 1909 Naranjo poseía 608 hectáreas cultivadas de café, lo que representaba el $30 \%$ del total de cultivos, para el año 1925 ya había en el cantón 1.590 hectáreas del grano (Badilla y Solórzano, 2010, p. 129), correspondientes al $61 \%$ del total de áreas cultivadas. No obstante, cabe mencionar que las actividades agrícolas como el café, aunque fueron fundamentales, también se complementaban con la ganadería, lo que se aprecia con las 1.973 hectáreas dedicadas a pastos, de acuerdo con el Censo Agropecuario de 1925 (Badilla y Solórzano, 2010, p. 129).

Durante la segunda mitad del siglo XIX, paulatinamente se fue consolidando una población que se vio en la necesidad de plantearse su propio sistema de organización y de apelar a los favores del Estado para buscar mayor estabilidad y viabilidad. Ejemplo de ello es la petición enviada al Congreso en 1863 por un grupo vecinos de la comunidad, con el fin de denunciar algunos terrenos cuya utilización principal sería con fines comunales, entre ellos construir una escuela, una iglesia y una cárcel (Torres, 2007, p. 34).

Sobre este punto resulta esencial considerar que ya en 1863 los vecinos de Naranjo tienen la intención de construir una cárcel en la comunidad; ello implica que los niveles de conflictividad y la incidencia de lo que en la época se consideraban delitos, empezaban a cobrar auge en la pequeña población rural y los habitantes sentían la necesidad de edificar, además de la escuela y el templo, la cárcel.

Lo anterior se complementa al evidenciar los primeros conflictos que se desarrollaron en la comunidad: "El hecho de que los pobladores de Naranjo, en 1863, denunciaran algunas tierras baldías, provocó la reacción de otros colonizadores que reclamaban como suyas esas tierras..." (Torres, 2007, p. 35). De esta forma, se observan los primeros conflictos que acaecieron por la disputa de la propiedad de las tierras y por la conflictividad que generó el capitalismo agrario.

Otro ejemplo relacionado con esta dinámica tuvo lugar en 1873, cuando algunas de las familias principales de Naranjo se opusieron rotundamente al pago de una cuota que pretendían cobrarles las autoridades nacionales, con el fin de construir un camino hacia Grecia. ${ }^{2}$ A pesar de la necesidad de conectar a Naranjo con la comunidad griega y otros poblados intermedios como Sarchí, los vecinos privilegiados se preguntaban por qué debían costear ellos los gastos del proyecto, y consideraban que la responsabilidad de la inversión debía ser estatal.

Dicho conflicto generó importantes disputas entre la alcaldía de Grecia y los vecinos de Naranjo. El jefe político griego, Domingo Suárez, argumentaba que el pago por realizar en el distrito de Naranjo era el más bajo del cantón y que era sabido que en el poblado vivían personas con importantes capitales, como se detalla respecto a un señor de apellido Blanco, "poseedor de una gran hacienda de café con beneficio y maquinaria cita en Sarchí; y en el Naranjo, buenos terrenos, casas, 
tienda é imprenta, cuyo capital no baja de cincuenta mil pesos, i está detallado en 25 colones" (Archivo Nacional de Costa Rica, 1873).

Las autoridades intentaban ejercer control directo sobre los poblados, y en este caso particular sobre el capital de Naranjo, por lo que se detallaban aquellos vecinos que poseían dinero o bienes como las máquinas de acerar, caso de Nicanor Araya y Leandro Corrales. Las autoridades consideraban a estos pobladores, que se negaban a pagar, como griegos (miembros revoltosos de su cantón). Los veían además como aquellos que se oponían al progreso (representado por el camino), dada su ignorancia y mezquindad: "Donde quiera hai $[s i c]$ majaderos y hombres miserables y retrógrados, pero a estos debe sofocarse en sus principios porque son el cáncer que infestan las sociedades" (Archivo Nacional de Costa Rica, 1873).

Más allá de esta descripción sobre las características atribuidas a los naranjeños, se observa la necesidad de controlar y asegurar capital para la realización de obras públicas. Es evidente para esta fecha la acumulación de cierta riqueza, así que los vecinos principales de Naranjo fueron llamados a pagar de acuerdo con sus recursos, por lo que aquellos con mejor condición socioeconómica debían contribuir en mayor medida para lograr la construcción del camino, lo cual generó su molestia. Este descontento puede ser considerado como un aliciente que se utilizaría para incentivar la idea de crear un nuevo cantón.

En cuanto al factor demográfico, Naranjo poseía de acuerdo con el Censo de Población de 1883 un total de 4.593 habitantes, de los cuales solo 2.943 vivían en poblaciones que actualmente pertenecen al cantón. Esta fecha se acerca a la del inicio del periodo en estudio, que es 1880 , por lo que da una idea de la población de ese entonces. De manera similar, aunque el periodo termina en 1924 con la instauración de un nuevo Código Penal, los datos solo están disponibles para 1927, cuando la población del cantón ascendía a 7.190 habitantes (Torres, 2007, p. 45). La Figura 1 sirve para ejemplificar mejor la dinámica de la población naranjeña.

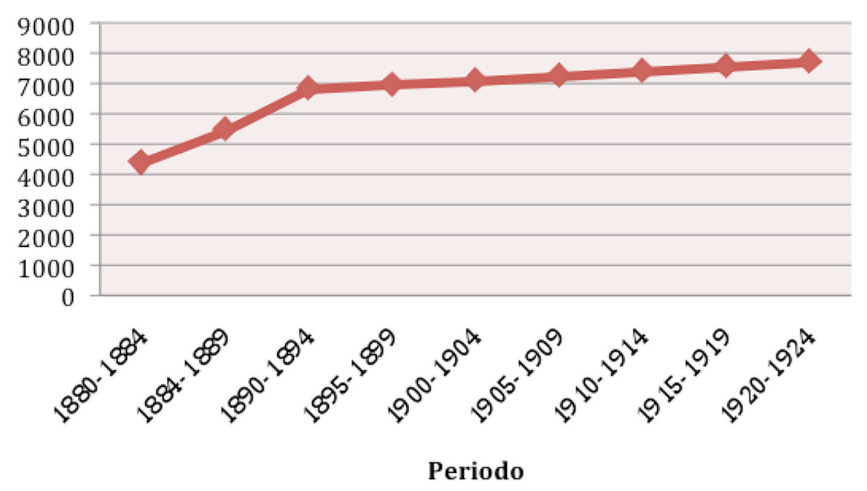

Figura 1. Población en Naranjo 1880-1924.

Fuente: Elaboración propia con base en (Torres, 2007, p. 46). 
La población de la localidad no experimentó un aumento tan radical en dicho periodo de 44 años. En parte este crecimiento relativamente moderado se debió a las migraciones hacia la Zona Norte, que colonizaron los territorios de las poblaciones en formación de San Carlos y Alfaro Ruiz. Además, se debe considerar que en el Censo de Población de 1883 estos territorios se tomaban como parte del cantón de Naranjo, lo que aumentaba los datos de población al incluir poblados que luego no pertenecerían al cantón.

Aunado a ello, la región se vio favorecida por una segunda migración importante, de nuevo procedente de otras zonas del Valle Central, producida entre 1885 y 1894 (Torres, 2007, pp. 43-44). Dicho aumento demográfico puede ser apreciado en la Figura 1. Esta migración, sumada al crecimiento natural de la población, provocó una competencia por las tierras y favoreció las primeras migraciones desde Occidente hacia Alfaro Ruiz y Ciudad Quesada, proceso de desplazamiento que se mantuvo durante las primeras dos décadas del siglo XX y que desembocó en la creación de nuevos cantones.

En el caso de Naranjo, dos hechos significativos marcaron la consolidación del poblado en la década de los ochenta del siglo XIX, uno de importancia religiosa y el otro de carácter civil. El primero se refiere a la formación de la parroquia en el año 1881 y el segundo a la declaración del cantonato en 1886, los cuales contribuyeron en la consolidación de la organización y demuestran el desarrollo de las actividades productivas. Resulta significativo que la organización religiosa se cristalizara antes que la civil y que Naranjo fuera parroquia antes de ser cantón.

La Figura 2 muestra la composición socioeconómica del cantón para finales del siglo XIX, donde destaca la predominancia de jornaleros.

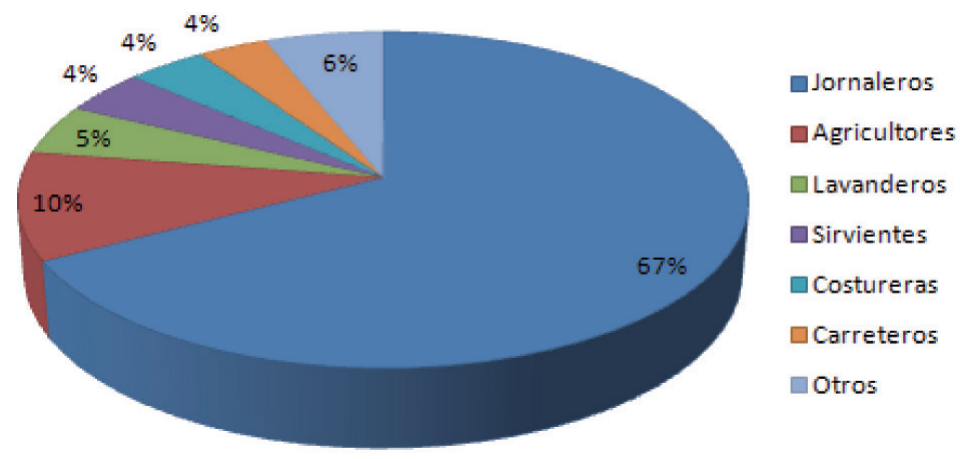

Figura 2. División ocupacional en Naranjo, 1892. Fuente: Elaboración propia con base en (Torres, 2007, p. 60). 
La división ocupacional refleja que la mayoría de la población trabajaba por un jornal, usualmente como peones agrícolas en fincas de café. Por ello, dicha estructura social favorecía los conflictos relacionados con el capitalismo agrario, como fueron las deudas y las disputas por tierras.

En este contexto de división del trabajo, el peso de contar con autoridades civiles y una Alcaldía transformó de manera significativa los aspectos relacionados con la denuncia y el manejo institucional de la conflictividad. Hasta 1886, las acusaciones de aquellos delitos cometidos en Naranjo se presentaban ante los Juzgados de Grecia, por pertenecer el poblado a dicha jurisdicción. Después de esta fecha, las querellas empezaron a ser dirimidas en la Alcaldía Única de Naranjo y algunos casos eran enviados, para su revisión y dictamen, al Juzgado del Crimen de Alajuela.

La presente investigación, al abarcar el periodo 1880-1924, se ubica en la jurisdicción de un Código Penal que tuvo ciertos altibajos y que demuestra la dificultad de los gobernantes liberales al implementar las leyes que creaban (Vargas, 2003, p. 305). Por ello, este periodo resulta interesante de analizar, para determinar la incidencia de la legislación y las resistencias al interior de la comunidad. Esto por cuanto en la Costa Rica rural de finales del siglo XIX, más que el orden, la legislación y el control institucional, privaban los conflictos vecinales, las diversiones, el alcohol y las "bajas pasiones" (Gil, 1997, p. 47). No obstante, dichas características no impiden que sea posible apreciar un considerable apego al derecho por parte de la población, en tanto los conflictos vecinales, principalmente por tierras a causa del desarrollo del capitalismo agrario, fueron canalizados mediante las denuncias ante las alcaldías y los juzgados correspondientes, dándole un carácter legalista a la sociedad agraria decimonónica.

Las relaciones comunales se desarrollaban entre el conflicto y la solidaridad, por lo que la dimensión de rivalidad propia de un caso como el asesinato, se sustenta en un tejido social que permite ciertos niveles de violencia y que posee formas particulares de canalizar los conflictos.

En medio de ella [la disputa] hubo una gama de actores y actitudes que van desde la víctima y su agresor, quienes llegaron a esgrimir flemáticas defensas de sus puntos de vista, hasta aquellos que desde los mecanismos de control trataban de controlar a los implicados en el hecho. (Gil, 1997, p. 51)

Tales relaciones tensas generaban el involucramiento de la comunidad y en muchos casos el disimulo o la indiferencia, cuando una disputa particular dejaba ver fisuras en el tejido social y en la escala de valores dominante. 
Algunos conflictos pasaron de disputas en las calles mediante la violencia directa a ser dirimidos en los tribunales, de tal forma que el derecho juega un papel cada vez más notorio en el mundo rural, conforme avanza el capitalismo.

Los mecanismos de control social son un factor importante a tomar en cuenta a la hora de analizar por qué los conflictos por tierras no degeneran necesariamente en violencia:

Allí donde no había un policía, habrá un Agente de Policía y si no ya habrá un sacerdote, un maestro, o un hombre de bien y letrado el cual será la autoridad moral que dictará y difundirá los nuevos preceptos impuestos por la moral dominante. (Gil, 1997, p. 57)

Las cabeceras de cantón fueron centros de poder importantes, donde las familias principales que controlaban las actividades agrícolas, en el caso de Naranjo prioritariamente el café, establecían su jurisdicción y dictaban las reglas sociales a interiorizar por el resto de la población, mediante las cuales hacían uso de su poder.

En este sentido, las normas servían además para mantener a raya a las clases populares, pues las sentencias pretendían establecer una diferenciación social y "acostumbrar" a los costarricenses a las nuevas normas:

Aunque las sentencias dictadas eran evitables con el pago de una multa, el resultado de los procesos para la mayoría de los acusados de escasos recursos fue una estadía prolongada (entre 30 y 90 días) en la penitenciaría. Los procesos, controlados por los agentes de policía, cayeron fuera de los tribunales y de sus reglas de evidencia, y dejaron mucha amplitud "administrativa" a las instancias policiales. (Palmer, 1999, p. 110)

Dadas las condiciones de arbitrariedad y la dependencia de recursos económicos para evitar ir a prisión, las reglas y los mecanismos de control difundidos por la elite liberal del país, fueron asimilados o repelidos de maneras diversas por las clases populares, las cuales utilizaban para tal fin los valores y costumbres comunales (Marín, 2007, pp. 146-147). En el caso de Naranjo, se observa la tendencia de los pobres a intentar protegerse de abusos laborales, o bien de pequeños propietarios que se esforzaban por mantener sus propiedades y no sucumbir a las presiones de aquellos con mayor capital.

El control social se llevó a la práctica mediante el miedo, al incentivar el temor hacia instituciones como la cárcel, el cual se aunaba al miedo por el impedimento de trabajar y con ello la imposibilidad de llevar sustento a la familia. Aunque provenientes de fuentes distintas, los mensajes de la escuela, la iglesia y la prensa se orientaron hacia una moralización que privilegiaba el uso del derecho y fustigaba contra la utilización de la fuerza bruta para la resolución de los conflictos. El rechazo hacia el delito es una de las actitudes que se desea fomentar a partir de los discursos sobre la criminalidad. 
El papel de las "personas de categoría" (Gil, 1997, p. 60) fue importante en la canalización y resolución de los conflictos. Se trata de aquellos individuos instruidos de la comunidad y en el caso de Naranjo el ejemplo más notorio fue Félix Arcadio Montero, quien fungía como abogado y representaba a familias distinguidas del cantón. Dado su liderazgo y el respeto que le tenían los parroquianos, participaba activamente en la mediación de las disputas y acrecentaba la idea de que el conflicto debía resolverse siempre por la vía legal. En estas personas letradas se combinaba la moral dominante con la costumbre campesina, para dar lugar a nuevas formas de convivir cotidianamente con la conflictividad.

En última instancia, se interioriza la idea de que no valía la pena pelear físicamente y exponer la vida, si se podía llevar a cabo un proceso legal en el cual se depositaba la confianza en un Juzgado. Este nivel de certidumbre en la labor del aparato judicial resulta digno de destacar para la época, en tanto refleja en qué medida la población había interiorizado las nociones del derecho como el medio legítimo para dirimir sus conflictos.

\section{DENUNCIA Y DELITO EN NARANJO}

Para efectos del análisis que se lleva a cabo en el presente artículo, a partir de los datos del Archivo Nacional de Costa Rica, se construyó una base de datos que sirvió de sustento para explicar la incidencia de las denuncias realizadas por los naranjeños en el periodo 1880-1924.

Para hacer más operativo el análisis, se llevó a cabo una categorización de las denuncias de acuerdo a los delitos inquiridos, de tal forma que se establecieron dos grandes categorías. La primera se denominó delitos contra la vida y el honor, y en ella se agruparon varias subcategorías; la segunda fue designada como delitos contra la propiedad y el patrimonio, con sus correspondientes subdivisiones. Para clarificar el establecimiento de dichas categorías, se presenta en la Tabla 1.

Cabe mencionar que tales categorías no son totalmente excluyentes, en tanto las denuncias podían implicar varios delitos; por ejemplo, una disputa por límites entre propiedades que termina en lesiones entre los involucrados o bien que una de las partes denuncia a la otra por "daños". Al respecto, los "nuevos" delitos producidos por el auge del capitalismo agrario conviven con la moralidad de una sociedad precapitalista y campesina, en la cual tenían un peso importante las nociones de honor y rectitud, y se practicaban formas de resolución de conflictos alternativas. 


\section{Tabla 1}

CATEGORÍAS DE DENUNCIAS POR DELITOS, 1880-1924

\begin{tabular}{ccl}
\hline CATEGORÍA & SUBCATEGORÍAS & \multicolumn{1}{c}{ DELITOS } \\
\hline \multirow{2}{*}{ Lesiones } & Lesiones y heridas \\
Delitos contra la vida & Daños y perjuicios & Injurias y calumnias \\
y el honor & Autoridad & Contra la autoridad, abuso de autoridad \\
& Vida & Asesinato, rapto, amenaza de asesinato con agresión \\
Delitos contra la & Moral & Violación, incesto, estupro, adulterio \\
propiedad y el & Deudas & Embargo, pagaré, reconocimiento \\
patrimonio & Tierras & Escrituras, allanamiento, desocupación, límites, fajas de agua \\
& Comercio & Nulidad, ventas, contrabando, pesos \\
\hline
\end{tabular}

Nota: Elaboración propia con base en causas judiciales de 1880-1924, base de datos del Archivo Nacional de Costa Rica.

\section{DELITOS CONTRA LA VIDA Y EL HONOR}

En relación con la primera categoría de delitos, se observa en la Figura 3, cómo los delitos contra la vida y el honor presentan una tendencia irregular, en la cual se dan crecimientos y descensos que pueden ser atribuibles a subregistros o a situaciones particulares en la dinámica comunitaria.

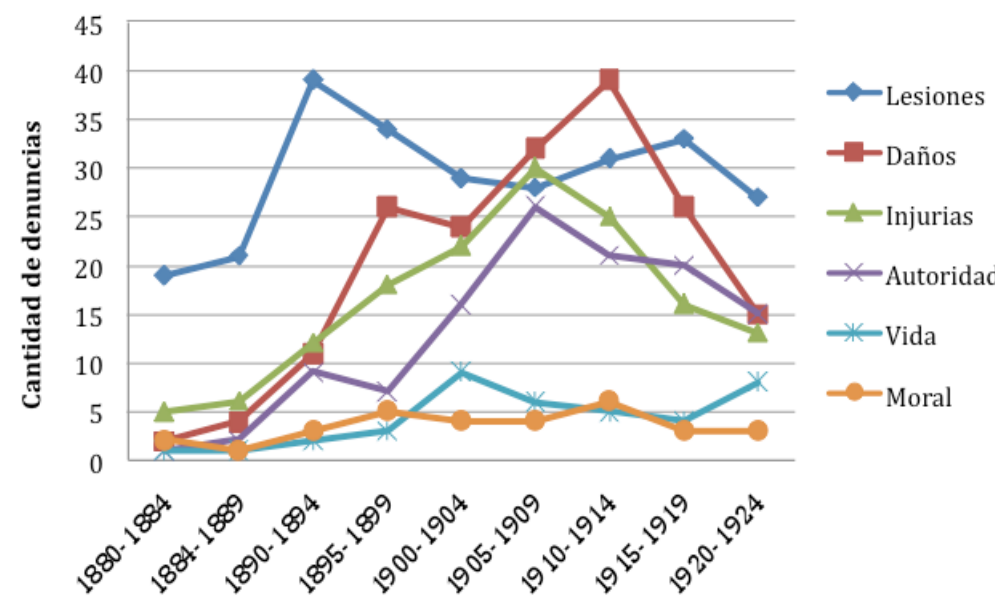

Figura 3. Denuncias por delitos contra la vida/honor en Naranjo, 1880-1924. Fuente: Elaboración propia con base en causas judiciales de 1880-1924, base de datos del Archivo Nacional de Costa Rica. 
Los delitos agrupados en esta categoría muestran una tendencia de crecimiento hasta el quinquenio de 1910-1915, cuando empezaron a disminuir significativamente, a excepción de aquellos en los que se atentaba directamente contra la vida, como rapto y homicidio, o la tentativa de cometerlos.

Más allá de estas transgresiones específicas, es factible apreciar la disminución de las denuncias que se produjo en los últimos años del periodo en la mayoría de amenazas contra la vida y el honor, lo que podría estar relacionado con la canalización y apaciguamiento de estas disputas, o bien con un cambio en la escala de valores que hacía que las personas denunciaran menos por estos motivos y más por otro tipo de infracciones relacionadas con el auge del capitalismo agrario.

Curiosamente, en el último quinquenio se aprecia un aumento en los delitos contra la vida, entre los que destacan principalmente los raptos, que se realizaban primordialmente contra niños como una forma de venganza o acción para perjudicar a los padres. Asimismo, se notan amenazas de muerte que van acompañadas de agresiones como una forma de intimidación directa, catalogadas como intentos de homicidio, situaciones que difícilmente desembocaban en un crimen de mayor envergadura. Para analizar procesos particulares, se detallan dos casos de asesinato comprobado en el cantón.

En el primero de ellos, que más revuelo causó entre los pobladores, se acusó a Ramón Marín de asesinar de un disparo a Abel Mora en 1919. La rencilla entre estos dos naranjeños estuvo teñida de rencores previos, suscitados por los amoríos entre Mora y la hija menor de Marín, el cual cargaba con el peso del "deshonor" de su hija adolescente y de la angustia por el sobreseimiento del caso contra Mora por violación y "prostitución" de menores.

Dichas circunstancias se vieron alimentadas por el expediente de riñas y conflictos que poseían ambos pobladores, lo cual demuestra que eran proclives a resolver altercados mediante el uso de la fuerza. No obstante, existía una noción de honor masculino que debía preservarse en las disputas, pues implicaba reconocimiento social: “...teniendo en cuenta que Mora me decía que estaba desarmado, dije a éste "yo no lucho con usted si no tiene armas". Él dijo que dentro de media hora estaría armado.” (Archivo Nacional de Costa Rica, 1919, f. 8).

Marín era un comerciante que tenía una posición económica estable en Naranjo, mientras que Mora se dedicaba a trabajos temporales en el campo. Esta situación tuvo impacto en el juicio, pues Marín consiguió como abogado al joven alajuelense León Cortés Castro. Se denota cómo la influencia de las "personas de categoría" (Gil, 1997, p. 60) era notoria en los pueblos rurales costarricenses a inicios del siglo XX, y tener un abogado de renombre era una importante certidumbre para evitar un dictamen perjudicial. 
La labor de Cortés como defensor fue fundamental, pues se encargó de justificar el disparo hecho por Marín de toda forma posible, a la vez que construía una imagen opuesta de los involucrados: "Mi defendido ha observado una conducta de hombre honrado, con dedicación al trabajo y enemigo de pendencias, ya que el occiso fue un individuo de temperamento pendenciero y provocativo, sin ocupación conocida y antes bien, jugador." (Archivo Nacional de Costa Rica, 1919, f. 45).

La descripción del fallecido intentó acentuar la idea de la provocación, en tanto la imagen del agresor no coincidía con las evidencias de múltiples causas por disputas en las que Marín se había visto involucrado. No obstante, la moral de la época enfatizaba la necesidad de parecer recto, aunque en la práctica cotidiana los patrones de masculinidad acentuaban el uso de la fuerza como mecanismo de socialización y resolución de conflictos por parte de los varones.

Un punto a recalcar es que el derecho, como elemento que pretende ser hegemónico en la resolución de conflictos, adquiere un carácter moderno que fue explotado por los primeros profesionales que lo ejercieron. Como Cortés Castro, quien citó en el juicio una sentencia del Tribunal de Madrid, fechada en 1878, en la cual según el jurista se estableció el principio de "provocación ilícita", cuando una persona actúa de cierta manera por provocación.

Al finalizar el proceso, a pesar de que el Juzgado de Alajuela sentenció a tres años de cárcel al imputado, curiosamente la Sala Segunda de la Corte Suprema de Justicia revocó el fallo y absolvió a Marín, a pesar de haberse probado que disparó directamente contra Mora. Incluso se le devuelve al imputado el revólver con el que realizó el disparo.

En el segundo caso de asesinato, se acusa a Abel Chacón por dar muerte de una puñalada a Juan Cordero. El enfrentamiento entre ambos se produjo en un lugar público y tiene todas las características de una refriega callejera en la cual intervinieron una gran cantidad de vecinos y, al exaltarse los ánimos, Chacón hirió mortalmente a Cordero (Archivo Nacional de Costa Rica, 1918b).

Las autoridades intentan reconstruir el hecho y averiguar qué provocó la riña, proceso que tuvo que ver con las dinámicas propias del ejercicio de la masculinidad, aunadas a la cultura de la ingesta de licor y el resarcimiento de enemistades del pasado.

Precisamente conflictos como este, que desembocó en la trágica muerte de Cordero, son los que el derecho moderno intentó encauzar hacia su mediación y posible resolución por parte de las autoridades competentes, por lo que el derecho buscó disminuir los niveles de violencia y reprimir los impulsos agresivos, encauzando las disputas hacia los tribunales y pretendiendo hacer que la población interiorizara la idea de que resultaba más beneficioso y seguro denunciar, que buscar revancha por medios propios. 
Más allá de los casos de homicidio, las lesiones y daños son causas de denuncia comunes en el periodo en estudio, en tanto la agresión constituía un medio de dirimir disputas. Ejemplo de ello fue la instrucción criminal por lesiones recíprocas contra Rodolfo Gutiérrez y Juan Mora. En esta reyerta, uno de ellos “...tomó la vara de medir i le descargó un golpe en el brazo y cabeza...", (Archivo Nacional de Costa Rica, 1885b, f. 4) mientras que el otro “...tomó un machete de los caídos en el suelo y con él le descargó un tiro..." (Archivo Nacional de Costa Rica, 1885b, f. 4). Tal nivel de violencia se presentaba de manera normal en las comunidades y constituía una forma de resolver conflictos a partir del uso de la fuerza.

En repetidas ocasiones, las denuncias por lesiones no fueron acreedoras de un castigo directo por parte de las instancias judiciales, al considerárseles un delito común en el cual resultaba usualmente difícil establecer grados de culpabilidad. Tal es el caso de la causa criminal seguida contra Alejandro Morales en 1883, en la que no se dictó sentencia alguna a pesar de las pruebas, pues se apeló a la "conducta intachable" del acusado. (Archivo Nacional de Costa Rica, 1883).

Otras evidencias de sobreseimiento se dieron en el caso de agresión de Eugenio Araya contra Margarita López, del ataque con arma blanca de Ramón Marín contra José Hidalgo y del policía Maximino Elizondo, quien agredió a José Ramírez (Archivo Nacional de Costa Rica, 1882; Archivo Nacional de Costa Rica, 1892; Archivo Nacional de Costa Rica, 1895).

De estos sumarios se extrae la conclusión de que las lesiones no fueron un delito comúnmente castigado y que tendieron a ser dispensadas por falta de pruebas. Sin embargo, en contadas ocasiones sí se establecieron castigos, como sucedió con la causa por lesión de José María Araya contra Ramón Marín. (Archivo Nacional de Costa Rica, 1890a).

Se puede notar cómo el carácter de las demandas usualmente apelaba al derecho y a la idea interiorizada por parte de las personas de que los conflictos se podían resolver mediante su denuncia. Lo anterior resulta válido para este caso, en el cual se trata de una agresión que, contrariamente a los otros ejemplos mencionados, no pasó desapercibida ante la demanda interpuesta y fue efectivamente sancionada, aunque el castigo no resultó tan riguroso: “...falló condenando al procesado por el delito al que se ha hecho mérito a la pena de veinticinco días de arresto o su equivalente en multa a pagar al ofendido". (Archivo Nacional de Costa Rica, 1890a, f. 5).

Además, se observa en dichos expedientes cómo la conducta de los policías distaba de ser irreprochable, situación que se evidencia a lo largo del periodo. El altercado entre Ramón Marín y Jerónimo Navarro, ocurrido en 1885, demuestra el cauce que tomaban las disputas y la actuación policial ante ellas: "Encontrándolo allí el gendarme de Policía, Jerónimo Navarro lo reconvino diciéndole que Bejarano 
iba a traer armas para tirarle, que se lo avisaba a fin de que se las quitara" (Archivo Nacional de Costa Rica, 1885a, f. 6).

El caso anterior remite al involucramiento policial y su papel en la mediación de conflictos, pues mientras un policía se encontraba en el lugar, no intervino directamente para evitar el enfrentamiento, sino que son otros vecinos los que actuaron para separar a los enfrentados (Archivo Nacional de Costa Rica, 1885a, f. 6v).

Las denuncias contra la autoridad policial fueron comunes en el periodo; por ejemplo, cuando un grupo de vecinos acusó al Agente Principal de Policía de San Jerónimo de Naranjo por "atropellos y vejaciones indignas", y porque además había tomado dinero de fondos comunes, se había embriagado y repartido licor (Archivo Nacional de Costa Rica, 1917). La policía también es denunciada por su convivencia con mujeres de "vida licenciosa" (Archivo Nacional de Costa Rica, 1923).

Otras acusaciones fueron aún más puntuales y revelan las posibilidades de acción que tenían los vecinos cuando no se encontraban a gusto con el comportamiento policial. Lo anterior demuestra que los mecanismos de vigilancia y control social eran bidireccionales, pues también se podían dar de parte de la población hacia la policía, que además estaban relacionados con la moral comunitaria que dictaba lo que era correcto y las formas de socialización en diferentes contextos.

Ello se demuestra cuando un policía denunció a su propio compañero por abandonar su puesto de trabajo en horas laborales: “...me consta que Teófilo Villalobos Díaz, polizonte, abandonó su puesto en la noche del nueve del corriente más llevándose consigo un revólver que se le había entregado y una cobija colorada..." (Archivo Nacional de Costa Rica, 1900, f. 2).

El denunciante había interiorizado ya las formas consideradas correctas para actuar por parte de una "autoridad", por lo que la conducta de su compañero le pareció reprochable y denunciable. El policía inculpado, ante la denuncia, abandonó la comunidad de Naranjo y se emitió contra él una orden de captura.

Al observar figuras de mayor peso político que los policías, se puede apreciar que en el periodo en estudio se contabilizaron al menos 30 casos de denuncias procesadas contra los jefes políticos de Naranjo ante el Juzgado de Crimen de Alajuela, principalmente por causas como abuso de autoridad y detención arbitraria. En tales situaciones podían verse implicados los diferentes niveles de mando, como se evidencia en la denuncia interpuesta por Pedro Ulate, contra el alcalde de Naranjo, Abel Castro:

[...] me preguntó con voces alteradas por qué mi esposa le había quitado á la de él un balde de ordeñar. Le respondí que esos eran asuntos de mujeres en los cuales no intervenía yo; se quejó de que en el trasto venía un poco de leche que iba á reclamar y le contesté que en todo caso era leche de vacas mías pues no me las ha pagado todavía. Entonces echó mano al revólver con violencia; 
al ver lo cual, y estando yo desarmado lo agarré por los lagartillos y llamé á la policía para que lo sosegara. No conseguí que lo calmaran sino que me llevaran á la cárcel donde se me detuvo por hora y media. (Archivo Nacional de Costa Rica, 1912a, f. 1)

A pesar de la declaración de hasta cinco testigos, que se expresaron a favor de Ulate y apoyaron su versión, además del policía que lo arrestó y el jefe político, el Juzgado de Alajuela declaró la causa sin suficientes pruebas y por tanto el proceso fue sobreseído. En casos como este se nota el peso de una figura política y la reticencia de los tribunales para establecer mayores sanciones que pudieran afectar la estabilidad y la organización de los poblados. También sale a la luz el trasfondo económico de un conflicto con la autoridad, cuando el querellante le reclama al alcalde no haberle pagado las vacas que le vendió, por lo que el origen del conflicto remite a situaciones financieras.

\section{DELITOS CONTRA LA PROPIEDAD Y EL PATRIMONIO}

En relación con los delitos contra la propiedad y el patrimonio, el periodo en estudio presenta la particularidad de un aumento constante en este tipo de causas, especialmente debido al auge de las actividades económicas capitalistas y al crecimiento del café como cultivo de exportación, así como a las dinámicas propias de la venta y apropiación de terrenos por parte de los pobladores. En la Figura. 4, se puede apreciar la dinámica que mostraron estos delitos en el lapso entre 1880 y 1924.

Se observa que los delitos asociados a la posesión de tierras y a las deudas, experimentaron un crecimiento notorio en el periodo, principalmente las deudas, que se dispararon de manera considerable, ya que hasta 1900 se registraba aproximadamente la misma cantidad de denuncias en ambos casos, pero para 1924 las deudas son más del doble de los conflictos por tierras. Esta tendencia sirve para analizar por qué en Naranjo, como en otras comunidades del país, el capitalismo agrario estaba reconfigurando las relaciones sociales, de tal forma que las dinámicas de conflictividad y las formas de utilización del derecho implicaban cada vez más una lógica individualista y de posesión de bienes materiales o dinero.

Las denuncias por deudas constituían la parte visible de un entramado más complejo de vínculos y relaciones de sociabilidad en el mundo rural, relacionados por ejemplo a valores como la confianza, la solidaridad y el compadrazgo. Dichos valores eran puestos a prueba cuando un comensal se endeudaba y no pagaba puntualmente, por lo que su vecino, quien le había prestado el dinero, pasa de amigo a acreedor, interponiendo una denuncia. Estas causas judiciales por deudas culminaban mayoritariamente con el dictamen de obligación de pago para la 


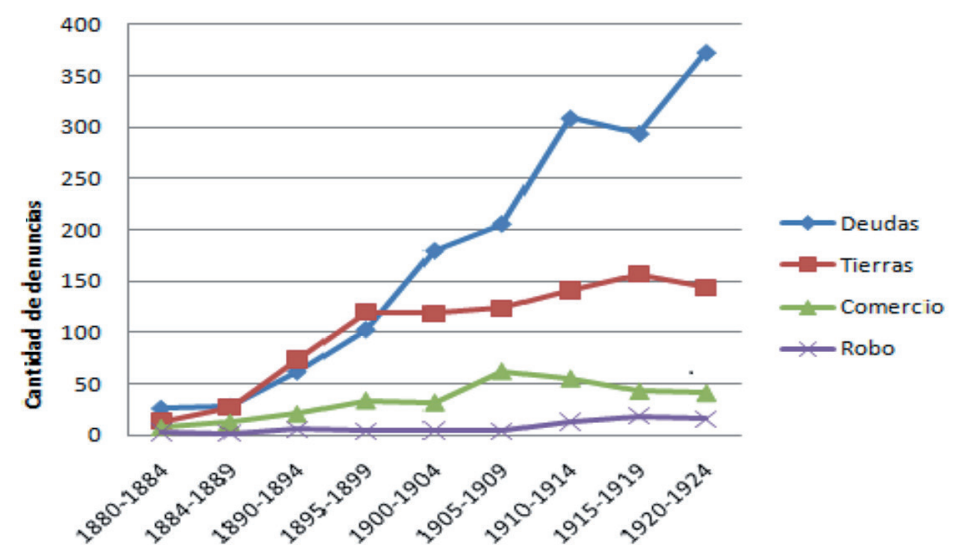

Figura 4. Denuncias por delitos contra la propiedad/patrimonio en Naranjo, 1880-1924. Fuente: Elaboración propia con base en causas judiciales de 1880-1924, base de datos del Archivo Nacional de Costa Rica.

persona deudora, pero tales medidas no necesariamente se cumplían con prontitud, por lo que las deudas de dinero podían fácilmente convertirse en un trampolín para otros niveles de conflictividad o bien ocultar relaciones asimétricas y de poder al interior de la sociedad.

Mientras tanto, las disputas por tierras podían aumentar el nivel de conflictividad, pues usualmente representaban mayores cantidades de dinero o bienes. Uno de los casos más connotados acaeció en 1889, cuando la señora Ramona Vargas, viuda de Judas Tadeo Corrales, reclamó el derecho sobre una propiedad que pertenecía a su esposo (Archivo Nacional de Costa Rica, 1889, Judicial N 30495).. La titularidad del terreno también fue exigida por Leandro y Nicolás Corrales, el primero de ellos hijo del difunto (Monge, 2010, p. 58).

Este conflicto se desarrolló en el seno de la elite naranjeña de la época, entre los descendientes y la segunda esposa del que se considera el fundador del pueblo. La señora Vargas demandó en 1888 su derecho a la herencia de la casa y una propiedad que poseía su marido. Argumentó que Leandro y Nicolás Corrales usurparon la propiedad. El caso se complicó por las descargas de los imputados y por sus peticiones de establecer un peritaje, aludiendo constantemente a que la finca no se encontraba inscrita en el registro de la propiedad. Para ayudarse en sus argumentos, los hombres implicados utilizaron los servicios del señor Félix Arcadio Montero, uno de los abogados considerados como personas de categoría en el pueblo, aquellos que asesoraban y mediaban en las disputas.

Otro ejemplo de conflicto por tierras se observa con la denuncia del señor Mercedes Esquivel contra Procopio Ramírez, por usurpación de terrenos y de una 
casa que poseía en Dulce Nombre de Naranjo, de la cual sin embargo admitió no tener título de propiedad. El afectado pidió resarcimiento por los daños que consideraba se le habían infringido con la ocupación por parte de Ramírez. El demandado no interpuso excepción alguna en el caso y la alcaldía determinó la necesidad del desahucio inmediato (Archivo Nacional de Costa Rica, 1890b, Judicial N 30491). Resalta también la demanda que interpuso Reyes Villalobos contra el jefe político y contra la alcaldía de Naranjo, en razón de que le obligaron a pagar un monto para el drenaje y construcción de caminos, por tener una finca que colindaba con la carretera principal del cantón. El denunciante argumentó que él había pagado puntualmente todas las contribuciones por el uso y tenencia de su finca, por lo que era injusto que le cobraran más arbitrariamente. Al respecto, las autoridades judiciales de Alajuela dictaminaron que no se podía probar la culpabilidad o inocencia del jefe político Salustio Camacho, y que Villalobos debía pagar su cuota para el mantenimiento del camino (Archivo Nacional de Costa Rica, 1896b, Juzgado de Crimen de Alajuela $\mathrm{N}^{\circ}$ 90).

En estos casos es posible notar el ejercicio del poder por parte de las autoridades locales, que les servía para legitimar el acceso a bienes y para establecer redes mediante las cuales se podía controlar y recibir beneficios en el manejo del comercio, propiedades, infraestructura, puestos políticos, entre otros.

Las situaciones de empoderamiento (cuando una persona empoderaba a otra en el manejo de sus bienes) también generaban conflictos en el mundo rural, pues se prestaban para confusiones, abuso de poder o disputas por herencias. La posesión de los bienes se convirtió en un factor que diferenciaba el mundo rural tradicional de la irrupción del derecho como mecanismo de legitimación de la propiedad privada.

Los robos fueron un delito común en el periodo en estudio, aunque debe considerarse que por motivos culturales, posiblemente muchos hurtos no fueron denunciados. Cabe considerar que en el espacio rural que habitaban los naranjeños, los vínculos vecinales usualmente permitían dar con los responsables, aunque ello no implicaba necesariamente sanciones.

Las víctimas de estas acciones eran comúnmente animales. En 1884, Nazario Araya denunció la desaparición de dos bueyes de su propiedad, los cuales se enteró que fueron subastados por el jefe político de Atenas (Archivo Nacional de Costa Rica, 1884, Municipal $N^{\circ}$ 12903). Por su parte, Mercedes Quesada acusó a Eusebio Alvarado sobre la nulidad de la venta de una yunta de bueyes (Archivo Nacional de Costa Rica, 1891, Judicial N 30460).

En un caso similar, pero con mayor implicación por parte de las autoridades, en 1896 David Chacón expuso la forma en la cual varias vacas fueron sustraídas de su propiedad, por lo que cuando se enteró de que la policía había decomisado un animal, acudió a la Alcaldía para reclamarlo como suyo. Le exigieron pruebas 
para determinar que él realmente era el dueño, muy a pesar de presentar testigos y de llevar el hierro con el cual estaba marcada la vaca, el jefe político, señor Lorenzo Castro, se negó a concederle la entrega, por lo que Chacón se vio obligado a denunciarlo ante el Juzgado de Alajuela. El jefe político argumentaba en su defensa que el animal también era reclamado por otras dos personas, Tranquilino Bonilla y Mercedes Acuña (Archivo Nacional de Costa Rica, 1896a, Juzgado de Crimen de Alajuela $N^{\circ} 88$ ).

En estos casos es factible apreciar la tentación que implicaba para los vecinos la posesión de una vaca, pues involucraba un capital que muchas personas no poseían. Además, resulta notorio que los implicados acudían a la vía legal aun cuando es de suponer que no todos podían ser los dueños del bovino, pero se arriesgaban calculando que podrían obtener un beneficio importante. Por otra parte, las autoridades no eran ajenas a este juego de intereses ni mostraban imparcialidad, sino que estaban permeadas por las dinámicas propias de la conflictividad comunal y de la realidad socioeconómica del cantón.

A pesar de las diferencias socioeconómicas o de estatus, cabe resaltar que el derecho en ocasiones obviaba la procedencia de los implicados y dictaba sentencia con criterios meramente técnicos. Un ejemplo de ello es el caso en el que se juzgó a Ana María Miranda, de ocupación sirvienta, por haberse robado un pañolón celeste de la casa en donde trabajaba, perteneciente a la familia Calvo. El proceso revela una estigmatización de la muchacha como una persona que, aparte de ser muy pobre, no era de confianza pues adolecía de "malas costumbres" y "mala conducta", de acuerdo con los testigos que comparecieron. A pesar de esta imagen negativa construida y reproducida socialmente, los tribunales no condenaron a Miranda, al no existir prueba contundente aparte de la declaración de un vecino que la vio salir de la casa por la noche, por lo que el caso no procedió y se otorgó sobreseimiento (Archivo Nacional de Costa Rica, 1912b, Juzgado de Crimen de Alajuela $\mathrm{N}^{\circ}$ 2584).

Otro ejemplo del estigma social que cargaba quien era acusado de hurto, y cómo este podía incidir en los tribunales, tuvo lugar en 1922, cuando Marcos Jiménez denunció el robo de 40 colones de la casa de su hermano Lucas. Dos cuñados de este último fueron acusados por algunos testigos y, de ellos, uno fue condenado a siete meses de prisión en San Lucas. En este caso, las nociones de persona "justa y trabajadora" (quien fue absuelto), en contraposición a "vago y de malas costumbres" (descripción que se hizo del condenado) tuvieron un peso importante en la sentencia definitiva (Archivo Nacional de Costa Rica, 1922, Juzgado de Crimen de Alajuela $\mathrm{N}^{\circ}$ 4273).

La evidencia muestra que los robos podían degenerar también en violencia física o en delitos más complejos, sancionados de manera más severa. Tal es el caso 


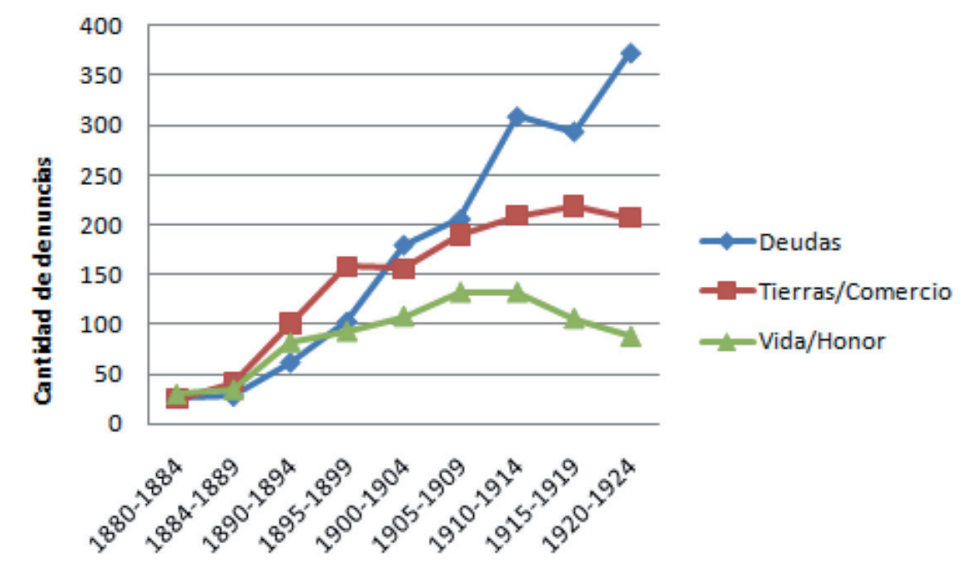

Figura 5. Denuncias por delito en Naranjo, 1880-1924.

Fuente: Elaboración propia con base en causas judiciales de 1880-1924, base de datos del Archivo Nacional de Costa Rica.

del altercado entre Pedro Zúñiga y Rafael Molina, acaecido en 1880, y en el cual se dieron amenazas de muerte e intentos de agresión por parte del primero hacia el segundo, a raíz de la acusación de hurto (Archivo Nacional de Costa Rica, 1880, Judicial $\mathrm{N}^{\circ}$ 16497). Para apreciar comparativamente el peso de las dos categorías principales de delitos considerados en la presente investigación, conviene prestar atención a la Figura 5.

Se presentan los delitos por deudas y los vinculados con la tierra y el comercio, como líneas individuales, mientras que la última línea representa los delitos contra la vida y el honor. Queda en evidencia que en la década de 1880, la diferencia entre la cantidad de denuncias era mínima, pero para finales del periodo en estudio, el repunte de las deudas y de los delitos vinculados con conflictos por tierras y generados por la actividad comercial y económica, superaban con creces la totalidad de querellas presentadas por infracciones contra la vida y el honor de las personas.

\section{LA POLÍTICA VINCULADA A LA NOCIÓN DE CRIMINALIDAD LIBERAL}

Otros delitos ocurridos en el cantón de Naranjo durante el periodo en estudio demuestran que la visión del crimen y la forma de sancionarlo tenían relación no solo con el desarrollo del derecho y los aparatos judiciales, sino con las formas de control, la política y la cultura popular. Ejemplo de políticas vinculadas a la sanción del delito fueron los llamados "destierros". 
El confinamiento era la expulsión de una persona de San José, o de otra ciudad vallecentralina, por un periodo determinado y como castigo por haber cometido un delito. Dichos procesos fueron comunes durante el periodo en estudio y la región occidental del Valle Central se convirtió en una zona de confinamiento. En 1905, el reo Jerónimo Carmona fue enviado a Naranjo por un periodo de 15 meses y 22 días, en los cuales debía permanecer en el pueblo: él fue procesado por el delito de lesiones lesiones (Archivo Nacional de Costa Rica, 1905a, Gobernación N 40246). Una situación similar vivió Rafael Chavarría, quien fue acusado en la capital por el delito de estafa y se le condenó a radicar en Naranjo por un mes y seis días (Archivo Nacional de Costa Rica, 1905b, Gobernación N 40249).

En 1913, Jenaro Cordero desobedece una orden de confinamiento que se había establecido contra él para que permaneciera en Zarcero, que pertenecía aún a Naranjo, y fue descubierto en Heredia: "El sábado recibí un telegrama del señor Agente Principal de Policía del Zarcero en que me decía que capturara á Jenaro Cordero Chaverri por haber quebrantado la pena de confinamiento que descontaba en aquel lugar" (Archivo Nacional de Costa Rica, 1913a, Judicial N ${ }^{\circ}$ 20213, f. 4). Al ser capturado, se remitió a San Lucas a descontar una pena por cuatro años.

La política se mezcló también con la vida cotidiana en Naranjo. Un incidente que lo demuestra ocurrió a inicios de 1918 cuando, como parte del alzamiento de Rogelio Fernández Güell contra la dictadura de los hermanos Tinoco, las autoridades reportaron movimientos revolucionarios en Naranjo, donde los insurgentes "...levantaron al pueblo, desarmaron a la policía, los repusieron, nombraron Jefe Político a Esteban Ramírez, desconectaron el aparato telegráfico, tomaron posesión de la oficina de la jefatura, de la Telegrafía, saquearon el parque y municiones del establecimiento..." (Archivo Nacional de Costa Rica, 1918a, Guerra y Marina No 9968).

El vandalismo también se dio en el cantón, como lo evidencia el incendio provocado en la escuela del distrito de El Rosario en 1913. Este caso se dilató entre las investigaciones y la presentación de pruebas, por lo que prescribió tras pasar más de siete años entre el hecho y el juicio (Archivo Nacional de Costa Rica, 1913b, Juzgado de Crimen de Alajuela N 3004).

Por su parte, los naranjeños jugaron un papel significativo en el engrosamiento de instituciones como el ejército, como lo demuestra el listado levantado entre 1908 y 1919, periodo en el cual 600 vecinos del cantón se convirtieron en soldados, pasando a formar parte del cuerpo castrense.

Finalmente, como ejemplo de esa necesidad constante de control e institucionalización y de preocupación por reprimir el delito, en 1923 el jefe político de Naranjo solicitó más policías al Ministro de Gobernación, argumentando que en 
el cantón habitaban 1.500 personas, existían ocho puestos de licores, pero solo estaban designados tres gendarmes. Por ello, requerían dos policías más y un sargento, con el fin de evitar el aumento en las ventas de licor clandestino, los juegos prohibidos y las faltas diversas (Archivo Nacional de Costa Rica, 1923, Gobernación $N^{\circ}$ 40796).

\section{CONCLUSIONES}

El control social ejercido por el aparato institucional del Estado durante el periodo liberal, tanto en Naranjo como en otras regiones del país, buscó establecer la interiorización de ciertas normas y hábitos que transformaban las prácticas populares de sociabilidad y las encauzaban hacia el derecho. El Estado intentaba el control no solo del desarrollo económico y de la viabilidad comunicativa y agraria, sino también de las costumbres y las relaciones vecinales, de ahí que en 1880 se estableció un nuevo Código Penal, el cual se aplicó en ocasiones de manera laxa y dependiendo del contexto y de los participantes en las querellas.

Existieron dos tendencias en relación con los delitos. Aquellos que atentaban contra el honor y la vida tendieron a aumentar lentamente, y al final del periodo disminuyeron; fueron canalizados hacia discusiones menos violentas, en las cuales la moral popular, el novel derecho moderno y las "personas de categoría" dirigían las riñas hacia un ámbito legal. Entre tanto, las infracciones vinculadas con el capitalismo agrario, como las deudas y los problemas por tierras y actividades comerciales, tuvieron un repunte considerable y generaron nuevas formas de conflicto, así como una propensión creciente a acudir a los tribunales a denunciar, cuando estaba en juego el patrimonio individual o familiar.

En los conflictos del mundo rural naranjeño es posible apreciar cómo diversos intereses convergían en las causas denunciadas y llevadas a juicio. Por ejemplo, se involucraban las autoridades, con su dosis de poder y de control, las leyes y su adaptación por parte del aparato judicial, la cultura popular que desarrollaba formas propias de ver, condenar moralmente o relativizar la delictividad, y finalmente, aquellos que vivían y trabajaban cotidianamente, tanto quienes poseían capital y lo invertían, como los que no lo tenían y dependían del peonaje u otros trabajos socialmente análogos.

Es por ello que el número de peones aumentó, así como el crédito, los préstamos entre vecinos y los altercados por tierras. Crecieron también la desconfianza entre vecinos y la idea de que los tribunales son buenos lugares para recuperar bienes o salvaguardar derechos patrimoniales (casas, propiedades, animales, cultivos, bienes, dinero, entre otros). 
Las reyertas que podían terminar en lesiones serias $\mathrm{u}$ homicidios disminuyeron y las nuevas formas de conflictividad enfatizaron la disputa por la propiedad privada y la complejización económica y cultural de la sociedad rural, en la que es presumible pensar que instituciones como la Iglesia debieron reconstituir su presencia social en la cotidianidad.

No obstante esta modernización, las nuevas prácticas del derecho convivieron con la moral popular, las nociones de masculinidad de la sociedad patriarcal y una visión particular del honor ligada a la rectitud (conducta intachable) que se vinculaba con la "palabra de honor" como forma de vida, pero también con el uso de la fuerza y la intimidación.

Naranjo formaba parte de la región occidental, y esta del país, por lo que en la comunidad se evidenció cómo las prácticas tradicionales se entremezclaron con el desarrollo productivo, la complejidad creciente de la cultura y la institucionalización de normas y mecanismos de control social. Se reflejó además la conflictividad del mundo liberal costarricense a pequeña escala, con lesiones, estafas, juegos "prohibidos", casos de embriaguez, indisciplina tributaria, oportunismo, abuso de autoridad y corrupción de quienes ostentaban puestos públicos; es decir, todo un universo social que distaba mucho de la pasividad y el confort, donde se predicaba una moral cristiana, pero no se practicaba, ya que más bien la cultura popular exudaba conflicto, adaptación y transgresión.

\section{REFERENCIAS}

Abarca, C. (2001). Castigados. Poder político y sanción penal en Costa Rica 1750-1880. Costa Rica: Zeta Servicios Gráficos S.A.

Archivo Nacional de Costa Rica. (1873). Municipal. Documento № 9927. Costa Rica: Archivo Nacional de Costa Rica.

Archivo Nacional de Costa Rica. (1882). Judicial. Documento $N^{\circ}$ 18121. Costa Rica: Archivo Nacional de Costa Rica.

Archivo Nacional de Costa Rica. (1880). Judicial. Documento $N^{\circ}$ 16497. Costa Rica: Archivo Nacional de Costa Rica.

Archivo Nacional de Costa Rica. (1883). Gobernación. Documento №34359. Costa Rica: Archivo Nacional de Costa Rica. 
Archivo Nacional de Costa Rica. (1884). Municipal. Documento $\mathrm{N}^{\circ} 12903$. Costa Rica: Archivo Nacional de Costa Rica.

Archivo Nacional de Costa Rica. (1885a). Judicial. Documento $N^{\circ}$ 17066. Costa Rica: Archivo Nacional de Costa Rica.

Archivo Nacional de Costa Rica. (1885b). Judicial. Documento $N^{\circ} 31184$. Costa Rica: Archivo Nacional de Costa Rica.

Archivo Nacional de Costa Rica. (1889). Judicial. Documento $N^{\circ}$ 30495. Costa Rica: Archivo Nacional de Costa Rica.

Archivo Nacional de Costa Rica. (1890a). Judicial. Documento $N^{\circ}$ 30303. Costa Rica: Archivo Nacional de Costa Rica.

Archivo Nacional de Costa Rica. (1890b). Judicial. Documento N 30491. Costa Rica: Archivo Nacional de Costa Rica.

Archivo Nacional de Costa Rica. (1891). Judicial. Documento $N^{\circ}$ 30460. Costa Rica: Archivo Nacional de Costa Rica.

Archivo Nacional de Costa Rica. (1892). Judicial. Documento $\mathrm{N}^{\circ}$ 16862. Costa Rica: Archivo Nacional de Costa Rica.

Archivo Nacional de Costa Rica. (1895). Judicial. Documento $\mathrm{N}^{\circ}$ 19499. Costa Rica: Archivo Nacional de Costa Rica.

Archivo Nacional de Costa Rica. (1896a). Juzgado de Crimen de Alajuela. Documento $\mathrm{N}^{\circ}$ 88. Costa Rica: Archivo Nacional de Costa Rica.

Archivo Nacional de Costa Rica. (1896b). Juzgado de Crimen de Alajuela. Documento $\mathrm{N}^{\circ} 90$. Costa Rica: Archivo Nacional de Costa Rica.

Archivo Nacional de Costa Rica. (1900). Juzgado de Crimen de Alajuela. Documento $\mathrm{N}^{\circ} 1290$. Costa Rica: Archivo Nacional de Costa Rica.

Archivo Nacional de Costa Rica. (1905a). Gobernación. Documento N 40246. Costa Rica: Archivo Nacional de Costa Rica. 
Archivo Nacional de Costa Rica. (1905b). Gobernación. Documento N 40249. Costa Rica: Archivo Nacional de Costa Rica.

Archivo Nacional de Costa Rica. (1912a). Juzgado de Crimen de Alajuela. Documento $\mathrm{N}^{\circ} 2375$. Costa Rica: Archivo Nacional de Costa Rica.

Archivo Nacional de Costa Rica. (1912b). Juzgado de Crimen de Alajuela. Documento $\mathrm{N}^{\circ} 2584$. Costa Rica: Archivo Nacional de Costa Rica.

Archivo Nacional de Costa Rica. (1913a). Judicial. Documento N 20213. Costa Rica: Archivo Nacional de Costa Rica.

Archivo Nacional de Costa Rica. (1913b). Juzgado de Crimen de Alajuela. Documento № 3004. Costa Rica: Archivo Nacional de Costa Rica.

Archivo Nacional de Costa Rica. (1917). Gobernación. Documento N 34594. Costa Rica: Archivo Nacional de Costa Rica.

Archivo Nacional de Costa Rica. (1918a). Guerra y Marina. Documento № 9968. Costa Rica: Archivo Nacional de Costa Rica.

Archivo Nacional de Costa Rica. (1918b). Juzgado de Crimen de Alajuela. Documento № 3242. Costa Rica: Archivo Nacional de Costa Rica.

Archivo Nacional de Costa Rica. (1919). Juzgado de Crimen de Alajuela. Documento № 4100. Costa Rica: Archivo Nacional de Costa Rica.

Archivo Nacional de Costa Rica. (1922). Juzgado de Crimen de Alajuela. Documento $\mathrm{N}^{\circ} 4273$. Costa Rica: Archivo Nacional de Costa Rica.

Archivo Nacional de Costa Rica. (1923). Gobernación. Documento № 40796. Costa Rica: Archivo Nacional de Costa Rica.

Badilla, M. y Solórzano, W. (2010). De territorio a región. Bases estructurales para la creación de las regiones Occidente y Norte de Costa Rica (1821-1955). Costa Rica: Sociedad Editora Alquimia 2000.

Cauvaud, F. (2003). Historia de la delincuencia y del control social: ensayo de historia antropológica. (El ejemplo de Francia, siglos XIX y XX). Revista de Historia, (47), 163-190. 
Emsley, C. (1996). La historia social evolutiva de la criminalidad y de los sistemas de justicia penal. Revista de Historia, (48), 156-157.

Gil, J.D. (1997). Morigerando las costumbres, canalizando las disputas. A propósito de los conflictos en los pueblos heredianos. 1885-1915. Revista de Historia, (35), 45-69.

Malavassi, A.P. (2003). Entre la marginalidad social y los orígenes de la salud pública. Leprosos, curanderos y facultativos en el Valle Central de Costa Rica (1784-1845). Costa Rica: EUCR.

Marín, J.J. (1994). Prostitución y pecado en la bella y próspera ciudad de San José (1850-1930). En I. Molina y S. Palmer. (Eds). El paso del cometa. Estado, política social y culturas populares en Costa Rica (1800/1950). Costa Rica: Editorial Porvenir.

Marín, J.J. (2007). Prostitución, honor y cambio cultural en la provincia de San José de Costa Rica: 1860-1949. Costa Rica: EUCR.

Molina, I. (1991). Costa Rica (1800-1850). El legado colonial y la génesis del capitalismo. Costa Rica: EUCR.

Monge, J. (2010). Correcciones a la descendencia desde los Bonifaz del Corral hasta los nietos de don Judas Tadeo Corrales Sáenz. Boletín Electrónico de la Academia Costarricense de Ciencias Genealógicas, (95). Recuperado de http://www.genealogia.or.cr/docs/boletines/ accg_boletin095.pdf

Naranjo, C. (1994). Pilar Jiménez, bandolero. El bandolerismo en el Valle Central de Costa Rica (1850-1890). En I. Molina y S. Palmer. (Eds.). El paso del cometa. Estado, política social y culturas populares en Costa Rica (1800/1950). Costa Rica: Editorial Porvenir.

Palmer, S. (1999). Adiós Laissez-Faire: la política social en Costa Rica (1880-1940). Revista de Historia de América, (24), 99-117.

Rodríguez, E. (1994). "Tiyita bea lo que me han echo". Estupro e incesto en Costa Rica (18001850). En I. Molina y S. Palmer. (Eds.). El paso del cometa. Estado, política social y culturas populares en Costa Rica (1800/1950). Costa Rica: Editorial Porvenir.

Rodríguez, E. (2000). Hijas, novias y esposas. Familia, matrimonio y violencia doméstica en el Valle Central de Costa Rica (1750-1850). Costa Rica: EUNA. 
Torres, J.L. (2007). Naranjo y su historia (1835-2004). Costa Rica: EUNED.

Vargas, C. (2003). Historia política, militar y jurídica de Costa Rica entre 1870 y 1914. En A.M. Botey. (Ed.). Costa Rica desde las sociedades autóctonas hasta 1914. Costa Rica: EUCR.

Viales, R. (2000). Poblar, comunicar y buscar capitales: tres fundamentos de la política agraria liberal en Costa Rica entre 1870-1930. Agronomía Costarricense, 24(1), 99-111.

\section{ACERCA DEL AUTOR}

Eduardo González Ayala: Profesor e investigador de la Sede de Occidente, Universidad de Costa Rica. Correo electrónico: edgonaster@gmail.com 
